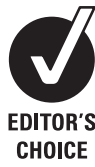

Emergency Department, Royal Children's Hospital, Murdoch

Children's Research Institute and University of Melbourne,

Melbourne, Australia

Correspondence to:

Dr F E Babl, Emergency

Department, Royal Children's

Hospital, Parkville, Victoria 3055,

Australia; franz.babl@rch.org.au

Accepted 10 February 2008

\title{
Limited analgesic efficacy of nitrous oxide for painful procedures in children
}

\author{
F E Babl, E Oakley, A Puspitadewi, L N Sharwood
}

\section{ABSTRACT}

Study objective: Nitrous oxide $\left(\mathrm{N}_{2} \mathrm{O}\right)$ is an attractive agent for procedural analgesia and sedation of children in the emergency department (ED). Despite increasing use, efficacy data for painful procedures are limited. This study aimed to determine pain scores during ED procedural sedation with $\mathrm{N}_{2} \mathrm{O}$ in the ED setting.

Methods: Prospective observational study of $\mathrm{N}_{2} \mathrm{O}$ use as a sole agent for procedural analgesia at a tertiary children's hospital ED. Pain scores were obtained from patients and parents using visual analogue or faces scales, as appropriate. Parent and staff satisfaction with sedation and analgesia were assessed.

Results: 124 children aged 1-17 years (mean 8.1) underwent procedural analgesia with $\mathrm{N}_{2} \mathrm{O}$ for 131 procedures. Most procedures were orthopaedic (44\%) or laceration repair (30\%). In $51 \%$ of patients $(95 \% \mathrm{Cl} 42 \%$ to 60 to 23\%) pain scores remained unchanged and in $34 \%$ (95\% Cl 26\% to 43\%) pain scores increased. Overall, $34 \%$ (95\% Cl $26 \%$ to $43 \%$ ) patients had intraprocedural scores of $50 \mathrm{~mm}$ or greater and $21 \%(95 \% \mathrm{Cl} 14 \%$ to $29 \%$ ) had pain scores of $70 \mathrm{~mm}$ or greater. Some procedures such as fracture reduction had a larger proportion of patients with high pain scores or $50 \mathrm{~mm}$ or greater $(45 \%)$ and $70 \mathrm{~mm}$ or greater $(29 \%)$. Staff rated both sedation and analgesia as "adequate" in 92\%. Parents contacted in follow-up were satisfied or very satisfied with procedures in $96 \%$ and sedations in $93 \%$.

Conclusion: Data indicate that parents and staff are generally satisfied with $\mathrm{N}_{2} \mathrm{O}$ for procedural use in the ED. The efficacy of $\mathrm{N}_{2} \mathrm{O}$ as a sole agent in very painful procedures is limited.

The use of nitrous oxide $\left(\mathrm{N}_{2} \mathrm{O}\right)$ for paediatric procedural sedation has been reported from many countries. ${ }^{1-6}$ Most research has used $50 \% \mathrm{~N}_{2} \mathrm{O}$ and there have been concerns regarding the variability of the analgesia and sedation provided. ${ }^{17}$ It has been suggested that $\mathrm{N}_{2} \mathrm{O}$ should not be used for procedures causing more than a low level of pain. ${ }^{8}$ Randomised controlled trials of the use of $\mathrm{N}_{2} \mathrm{O}$ for painful procedures in the paediatric emergency department (ED) have been reported since 1998, ${ }^{2}$ and in recent years the use of $70 \% \mathrm{~N}_{2} \mathrm{O}$ has become accepted and more widespread, with its use expanded to other settings. ${ }^{910}$ However, the efficacy of $\mathrm{N}_{2} \mathrm{O}$ for painful procedures has yet to be completely defined.

The primary objective of our study was to characterise the efficacy of $\mathrm{N}_{2} \mathrm{O}$ for procedural sedation and analgesia (PSA) in a paediatric ED.

\section{MATERIALS AND METHODS \\ Design and setting}

We conducted a prospective observational study in the ED of a large, urban children's hospital with an annual ED census of 60000 patients. All children presenting to the ED from August 2003 to March 2004 who received $\mathrm{N}_{2} \mathrm{O}$ for PSA were eligible for enrolment. The only formal exclusion criteria was the use of additional sedative agents. This study was approved by the hospital human research ethics committee.

When a child required PSA with $\mathrm{N}_{2} \mathrm{O}$, the examining doctor informed one of the researchers or trained research assistants who obtained informed verbal consent and made arrangements for a follow-up phone call. $\mathrm{N}_{2} \mathrm{O}$ administration was available via demand valve fixed $50 \% \mathrm{~N}_{2} \mathrm{O}$ / $50 \%$ oxygen, marketed as Entonox and via a continuous-flow system using the Quantiflex MDM machine, which delivers $0-70 \% \mathrm{~N}_{2} \mathrm{O}$ and includes a scavenging system to decrease environmental contamination.

A case report form was developed to record data before, during, and after PSA with $\mathrm{N}_{2} \mathrm{O}$. This included age, past medical problems, American Society of Anaesthesiologists (ASA) class, procedure, drugs used in addition to $\mathrm{N}_{2} \mathrm{O}$, highest concentration of $\mathrm{N}_{2} \mathrm{O}$ used and deepest level of sedation attained. Pain scoring by patient and parent was recorded 5 minutes before the procedure and immediately after its completion.

\section{Data}

Patients were classified according to ASA physical status classification (class 1, normal healthy patient; class 2 , patient with mild systemic disease with no functional limitation; class 3 , patient with severe systemic disease with definite functional limitation; 4, patient with severe systemic disease that is a constant threat to life; 5, moribund patient who is not expected to survive without the operation).

To measure the level of sedation, a sedation scale with seven levels of sedation ranging from 6 to 0 (table 1) developed at the Children's Hospital of Wisconsin was used. ${ }^{11}$ Decreasing sedation scores have been shown to be associated with an increasing rate of adverse events. ${ }^{11}$ Depth of sedation was assessed on an ongoing basis during the procedure; the deepest level of sedation achieved was recorded on the case report form.

Adverse events were defined a priori as serious or mild. Serious adverse events included patient oxygen desaturation below 95\%, apnoea, stridor, airway misalignment requiring repositioning, laryngospasm, bronchospasm, cardiovascular 
Table 1 Children's Hospital of Wisconsin sedation scale ${ }^{11}$

\begin{tabular}{ll}
\hline $\begin{array}{l}\text { Sedation } \\
\text { score }\end{array}$ & Patient's level of response \\
\hline 6 & $\begin{array}{l}\text { Anxious, agitated or in pain } \\
5\end{array}$ \\
4 & $\begin{array}{l}\text { Spontaneously awake without stimulus (talking) } \\
\text { Drowsy, eyes open or closed, but easily arouses to consciousness } \\
\text { with verbal stimulus }\end{array}$ \\
3 & $\begin{array}{l}\text { Arouses to consciousness with moderate tactile or loud verbal } \\
\text { stimulus }\end{array}$ \\
1 & Arouses slowly to consciousness with sustained painful stimulus \\
0 & Arouses, but not to consciousness, with painful stimulus \\
\hline
\end{tabular}

instability, pulmonary aspiration, unplanned hospital admission, endotracheal intubation, permanent neurological injury or death. Inadequate sedation was not regarded as an adverse event.

The primary outcome measure was pain as scored by children 5 years of age and over and by parents for children under 5 years of age. A visual analogue scale (VAS) was used for the selfreporting of pain in children 7 years of age and older and for parental scoring of children under 5 years of age. Children 57 years of age used the Faces Pain Scale-Revised (FPS-R).

The VAS scale is a $100-\mathrm{mm}$ horizontal black line that has extreme values of "no pain" and "very much pain". ${ }^{12}$ The VAS has been validated for use in adults and in children. ${ }^{13} 14$

The FPS-R scale is validated for children between 5 and 12 years of age. It consists of six faces representing various levels of discomfort or sadness, with the endpoints labelled "no pain" and "very much pain". ${ }^{15-17}$ The values of the FPS-R scale were converted into a 0-100 mm scale.

Secondary outcome measures were parent and staff satisfaction with PSA and successful completion of the procedure or not. Satisfaction was measured on a five-point Likert scale of "very satisfied", "satisfied", "neither satisfied nor dissatisfied", "dissatisfied", to "very dissatisfied".

Patients were telephoned by one of the researchers within $72 \mathrm{~h}$ to examine parent satisfaction with the procedure itself and the analgesia and sedation.

\section{Analysis}

All data were entered into an Access software database (Windows version 2003). Median values are reported with interquartile ranges (IOR) and proportions are presented with 95\% CI when appropriate. We used $\chi^{2}$ tests for dichotomous variables, t tests for parametric variables and Mann-Whitney $U$ tests for non-parametric variables. For all tests, values of $p$ less than 0.05 were considered statistically significant. Statistical calculations were performed using STATA software (version 10.0).

\section{RESULTS}

A total of 220 patients who received $\mathrm{N}_{2} \mathrm{O}$ for PSA were enrolled during the 8-month data collection period. The study group consisted of 124 patients for whom pain scores before and during the procedure were available and after the exclusion of nine patients who had received intravenous morphine $(n=9)$ within $2 \mathrm{~h}$ before the procedure (table 2).

The 124 patients underwent 131 procedures during 124 episodes of PSA. The 124 primary procedures, as shown in table 2, were mostly orthopaedic procedures (44\%) and laceration repairs $(30 \%)$. Of the nine patients who underwent more than one procedure, eight also had an intravenous line
Table 2 Characteristics of ED patients receiving $\mathrm{N}_{2} \mathrm{O}$ for PSA (n $=124)$

\begin{tabular}{|c|c|}
\hline & n (\%) \\
\hline \multicolumn{2}{|l|}{ Age, years } \\
\hline Mean, range & $8.1(1.3-17.9)$ \\
\hline Median, IQR & $8.3(4.9-11.0)$ \\
\hline \multicolumn{2}{|l|}{ Sex } \\
\hline Male & $80(64.5)$ \\
\hline \multicolumn{2}{|l|}{ ASA status§ } \\
\hline 1 and 2 & $118(95.9)$ \\
\hline 3 & $5(4.1)$ \\
\hline \multicolumn{2}{|l|}{ Percentage of $\mathrm{N}_{2} \mathrm{O}^{*}$} \\
\hline 70 & $100(80.6)$ \\
\hline 60 & $6(4.8)$ \\
\hline 50 & $18(14.5)$ \\
\hline \multicolumn{2}{|l|}{ Adjunctive agents $\dagger$} \\
\hline $\mathrm{N}_{2} \mathrm{O}$ alone & $109(87.9)$ \\
\hline Codeine & $15(12.1)$ \\
\hline \multicolumn{2}{|l|}{ Primary procedures } \\
\hline Laceration repair & $37(29.8)$ \\
\hline Fracture reduction & $31(25)$ \\
\hline Intravenous line insertion & $15(12.1)$ \\
\hline Plaster/backslab & $15(12.1)$ \\
\hline Relocation joint & $8(6.4)$ \\
\hline Removal of foreign body & $7(5.6)$ \\
\hline Removal of plaster, suture & $3(2.4)$ \\
\hline Abscess drainage & $3(2.4)$ \\
\hline Wound debridement & $1(0.8)$ \\
\hline Joint aspiration & $1(0.8)$ \\
\hline Other & $3(2.4)$ \\
\hline \multicolumn{2}{|l|}{ Sedation depth $\$ \S$} \\
\hline 0 & $1(0.8)$ \\
\hline 2 & $1(0.8)$ \\
\hline 3 & $6(4.9)$ \\
\hline 4 & $52(42.3)$ \\
\hline 5 & $58(47.1)$ \\
\hline 6 & $5(4.1)$ \\
\hline \multicolumn{2}{|l|}{ Adverse events } \\
\hline None & $103(83.1)$ \\
\hline Vomiting & $7(5.6)$ \\
\hline Dizziness & $5(4.0)$ \\
\hline Nausea & $4(3.2)$ \\
\hline Agitation/hallucination & $2(1.6)$ \\
\hline Other & $3(2.4)$ \\
\hline
\end{tabular}

*Highest nitrous oxide $\left(\mathrm{N}_{2} \mathrm{O}\right)$ concentration administered.

$\dagger$ Adjunctive agents: codeine (alone or in combination with paracetamol) if given within $2 \mathrm{~h}$ before sedation.

S.Sedation depth (see Methods).

ASA, American Society of Anesthesiologists; ED, emergency department; PSA, procedural sedation and analgesia. §one missing.

placed and one had a plaster slab applied. Some patients received adjunctive codeine by mouth within $2 \mathrm{~h}$ before the procedure, as listed in table 2. All patients who underwent intravenous line insertion had topical anaesthesia (amethocaine 4\%) applied before the procedure, although not all insertions occurred through anaesthetised skin. All laceration repairs were preceded by the application of topical wound anaesthesia (adrenalinelignocaine-amethocaine gel) or infiltration of local anaesthesia with lignocaine. The level of deepest sedation was recorded in 123 patients (99\%) (table 2); $94 \%$ of patients had scores equivalent to mild to moderate sedation (depth of sedation score 3 to 5). Two patients, both of whom had received $\mathrm{N}_{2} \mathrm{O}$ $70 \%$, had sedation scores equivalent to deep sedation (depth of sedation scores $0-2$ ). None of the 124 patients in this study 
Table 3 Pain scores during PSA with $\mathrm{N}_{2} \mathrm{O}$ by primary procedure $\left(\mathrm{n}=124^{*}\right.$ )

\begin{tabular}{lccccc}
\hline \multirow{2}{*}{ Procedures } & \multicolumn{7}{c}{ Pain score during procedure* } \\
\cline { 2 - 6 } & $\mathbf{n}$ & $\mathbf{0}(\%)$ & $\mathbf{1 - 4 9 ( \% )}$ & $\mathbf{5 0 - 6 9 ( \% )}$ & $\geqslant \mathbf{7 0}(\%)$ \\
\hline Laceration repair & 37 & $19(51.3)$ & $9(24.3)$ & $3(8.1)$ & $6(16.2)$ \\
Fracture reduction & 31 & $10(32.6)$ & $7(22.6)$ & $5(16.1)$ & $9(29.0)$ \\
Intravenous line insertion & 15 & $8(53.3)$ & $5(33.3)$ & $1(6.7)$ & $1(6.7)$ \\
Application of plaster, backslab & 15 & $7(46.7)$ & $3(20)$ & $2(13.3)$ & $3(20)$ \\
Joint dislocation reduction & 8 & $1(12.5)$ & $5(62.5)$ & - & $2(25)$ \\
Foreign body removal & 7 & $1(14.3)$ & $2(28.5)$ & $2(28.5)$ & $2(28.5)$ \\
Removal of plaster/suture & 3 & $1(33.3)$ & $1(33.3)$ & $1(33.3)$ & - \\
Abscess drainage, incision & 3 & - & - & $1(33.3)$ & $2(66.7)$ \\
Wound debridement & 1 & - & - & - & $1(100)$ \\
Arthrocentesis & 1 & - & $1(100)$ & - & - \\
Other & 3 & $1(33.3)$ & $1(53.3)$ & $1(33.3)$ & - \\
Total & 124 & $48(38.7)$ & $34(27.4)$ & $16(12.9)$ & $26(21)$ \\
\hline
\end{tabular}

* Patient pain score if 5 years of age or older $(n=93)$ and parent pain score if less than 5 years of age ( $n=31$ ).

$\mathrm{N}_{2} \mathrm{O}$, nitrous oxide; PSA, procedural sedation and analgesia.

suffered a serious adverse event (one-sided 97.5\% CI 0\% to $2.9 \%)$. Twenty-one patients $(16.9 \%$, 95\% CI $10.8 \%$ to $24.7 \%)$ experienced 21 mild and temporary adverse events in the ED (table 2).

\section{Pain scores during procedural sedation with $\mathbf{N}_{\mathbf{2}} \mathbf{O}$}

Preprocedurally, patients' pain scores ranged from 0 to $100 \mathrm{~mm}$ (median 32.5, IOR 10-70) and intraprocedural pain scores ranged from 0 to $100 \mathrm{~mm}$ (median 20, IOR 0-60). In 63 cases (50.8\%, 95\% CI $42 \%$ to $60 \%$ ), the pain scores decreased during the procedure, compared with baseline. Fifty-five (44.3\%, 95\% CI $35.4 \%$ to $53.5 \%$ ) of these cases experienced a decrease of $20 \mathrm{~mm}$ or more; in $89 \%$ of these cases the reduction was at least $50 \%$ of the preprocedural pain score. In $19(15.3 \%$, 95\% CI $10 \%$ to $23 \%$ ) cases pain scores remained unchanged during the procedure compared with baseline; nine of these had no pain before or during procedure. For 42 cases $(33.8 \%$, 95\% CI $25.6 \%$ to $42.9 \%$ ) the pain scores increased; 35 of whom experienced a pain increase of $20 \mathrm{~mm}$ or more $(28.2 \%, 95 \%$ CI $20.5 \%$ to $37 \%)$. Overall, 42 (33.8\%, 95\% CI $25.6 \%$ to $43 \%$ ) patients had intraprocedural scores of $50 \mathrm{~mm}$ or more and 26 (20.9\%, 95\% CI $14.1 \%$ to $29 \%$ ) had pain scores of $70 \mathrm{~mm}$ or greater (table 3 ). Of those patients who required fracture manipulation ( $\mathrm{n}=31), 14(45 \%)$ experienced increased pain during the procedure, eight of those experiencing a more than $20 \mathrm{~mm}$ increase compared with their preprocedural pain score.

An analysis of pain scores considering the procedures undertaken is provided in table 3 . Of the procedures used at least 15 times, laceration repair and intravenous line insertion showed intraprocedural pain scores of $0 \mathrm{~mm}$ in approximately $50 \%$ of cases; fracture reduction showed $45 \%$ of patients with intraprocedural pain scores of $50 \mathrm{~mm}$ or more. Although infrequently undertaken procedures in this study, both abscess drainage and wound debridement had very high intraprocedural pain scores. We compared pre and intraprocedural pain scores (dichotomised as $<50 \mathrm{~mm}$ and $\geqslant 50 \mathrm{~mm}$ ) according to the procedure performed, using those procedures performed 15 times or more ( $n=98$ ) (tables 3 and 4 ). Comparing across procedures, there was a significant difference in the preprocedural pain scores $(p=0.01)$; however, no significant difference was found between intraprocedural pain scores $(p=0.11)$.

The 42 patients (across all procedures) who experienced an intraprocedural pain score of $50 \mathrm{~mm}$ or more had a median preprocedural pain score of $48.5 \mathrm{~mm}$ (IOR 20-70), whereas the 82 patients with intraprocedural pain scores of $50 \mathrm{~mm}$ or less had a median preprocedural pain score of $28.5 \mathrm{~mm}$ (IOR 10-60, $p=0.04)$. Children under 5 years were more likely to have intraprocedural pain of $50 \mathrm{~mm}$ or more than older children $(p=0.049)$.

\section{Staff and parent satisfaction}

Ninety per cent of the 113 staff members who responded thought that both the analgesia and the sedation provided was adequate. Of the 42 patients who had pain scores of $50 \mathrm{~mm}$ or more during the procedure, $34(80.9 \%)$ were thought to have received adequate analgesia from $\mathrm{N}_{2} \mathrm{O}$ as stated by ED nurses. Three of 124 procedures (2.4\%) had to be abandoned due to inadequate sedation or analgesia.

On follow-up, 119 (96.0\%) parents could be reached, of whom $96 \%$ were satisfied or very satisfied with the procedure, $92 \%$ were satisfied with the sedation and $93 \%$ would be happy for their child to have PSA with $\mathrm{N}_{2} \mathrm{O}$ again. When asked to question their children regarding their recollection of the procedure, $74(62.1 \%)$ were able to recall it, 14 (11.8\%) were unsure and $31(26.0 \%)$ were unable to recall the procedure.

\section{DISCUSSION}

In the past decade $\mathrm{N}_{2} \mathrm{O}$ has gained popularity for use in paediatric PSA. A number of studies have trialled it, often

Table 4 Pain scores before and during PSA with $\mathrm{N}_{2} \mathrm{O}$ by frequent procedure (median and IQR)

\begin{tabular}{|c|c|c|c|c|}
\hline \multirow[b]{2}{*}{ Procedures (n) } & \multicolumn{2}{|c|}{ Preprocedural pain score } & \multicolumn{2}{|c|}{ Intraprocedural pain score } \\
\hline & Median & IOR & Median & IOR \\
\hline Laceration repair (37) & 20 & $10-45$ & 0 & $0-40$ \\
\hline Fracture reduction (31) & 35 & $20-70$ & 30 & $0-70$ \\
\hline Intravenous line insertion (15) & 30 & $0-95$ & 0 & $0-20$ \\
\hline Application plaster/backslab (15) & 70 & $20-100$ & 10 & $0-60$ \\
\hline
\end{tabular}

IOR, interquartile range; $\mathrm{N}_{2} \mathrm{O}$, nitrous oxide; PSA, procedural sedation and analgesia. 
against other techniques, for laceration repair, fracture reduction, dental procedures and vascular access. ${ }^{3-5}{ }^{18-22}$ Most of this literature is with $\mathrm{N}_{2} \mathrm{O}$ and oxygen mixtures in concentrations of up to $50 \%$ via demand valve or continuous flow. More recently, interest has been shown in higher concentrations of $\mathrm{N}_{2} \mathrm{O}$ - up to $70 \%$ - given by continuous flow mixers. ${ }^{9} 1023$ Studies have documented the ability to perform procedures safely using $\mathrm{N}_{2} \mathrm{O}$; however, its true efficacy as an analgesic has not been determined. ${ }^{1023} 24$

This study is the first to try and assess the efficacy of $\mathrm{N}_{2} \mathrm{O}$ in all use in a paediatric ED. $\mathrm{N}_{2} \mathrm{O}$ was used in a wide variety of procedures, with highly variable pre and intraprocedural pain scores. One third of patients had an increase in pain during the procedure, $83 \%$ of these having an increase of $20 \mathrm{~mm}$ or more. One third of patients reported intraprocedural pain greater than $50 \mathrm{~mm}$, with $21 \%$ reporting pain of $70 \mathrm{~mm}$ or more. Procedures considered to be potentially very painful, such as fracture reduction and foreign body removal, had a larger proportion of patients with pain rated over $50 \mathrm{~mm}$.

Staff rated analgesia as adequate in the majority of procedures with $\mathrm{N}_{2} \mathrm{O}$ overall. Notably, even in patients who reported pain scores equal to or greater than $50 \mathrm{~mm}, 81 \%$ of staff thought that analgesia was adequate. Parental satisfaction was also very high; most parents were happy to have the agent used again in their child.

Previous studies have suggested that for fracture reduction pain scores are variable, with up to $10 \%$ of children having no analgesic or sedative effect from $\mathrm{N}_{2} \mathrm{O}$. In general, pain scores show approximately $50 \%$ of patients having at least moderate pain. ${ }^{3}{ }^{19}$ However, $\mathrm{N}_{2} \mathrm{O}$ has been shown to be highly effective when accompanied by additional analgesic interventions for both fracture reduction ${ }^{425}$ and laceration repair. ${ }^{20} \mathrm{~N}_{2} \mathrm{O}$ and adjunctive analgesia is reported to be as effective as both Bier's block ${ }^{19}$ and ketamine plus midazolam ${ }^{4}$ for fracture reduction.

Only three $(2.4 \%)$ procedures in this study were abandoned due to inadequate PSA. This is in keeping with other $\mathrm{N}_{2} \mathrm{O}$ studies, ${ }^{3}{ }^{10}$ but higher than reported by Cravero et al, ${ }^{26}$ who documented a $0.9 \%$ failure rate in 30000 episodes of paediatric sedation/anaesthesia outside the operating room. It is better than the suggested $10 \%$ of children who have no analgesic effect from $\mathrm{N}_{2} \mathrm{O} .^{3}$

It has been documented that a reasonable proportion of children, and approximately one third from our data, experience moderate to severe pain during procedures. ${ }^{1}$ Perhaps it is time to consider $\mathrm{N}_{2} \mathrm{O}$ as an adjunctive only in very painful procedures, and to explore ways to provide additional analgesia in concert. $\mathrm{N}_{2} \mathrm{O}$ can be a useful analgesic and anxiolytic during the intravenous access needed to provide deeper sedation. ${ }^{27}$ Recent literature would support the use of intranasal opioid as a preprocedural analgesic in the ED setting ${ }^{28} 29$ and perhaps we should now be looking at combining such analgesics with $\mathrm{N}_{2} \mathrm{O}$ for non-parenteral PSA in painful procedures.

This observational study has several limitations. It would be ideal to assess efficacy in a randomised controlled trial. However, this would be difficult across heterogeneous procedures. Although this study includes all age ranges in which $\mathrm{N}_{2} \mathrm{O}$ would be useful, self-report pain assessment tools are agelimited and continuous (VAS scale) and ordinal (FPS-R) scales are difficult to compare. In addition, self-report scales are problematical in children under 5 years of age and parent scores are limited proxies. Child and parent scores depended on their degree of understanding of the scales, despite the use of standardised instructions by the researchers before commencing $\mathrm{N}_{2} \mathrm{O}$ PSA. A further limitation is the measurement of pain scores only, without taking into account the level of distress children experienced. However, it is difficult for children, parents and staff to differentiate distress from pain. It may also be difficult for parents to judge satisfaction with the procedure or the sedation when their understanding and comparative experience with the ideal performance of PSA with $\mathrm{N}_{2} \mathrm{O}$ is limited. Too few patients received $\mathrm{N}_{2} \mathrm{O} 50 \%$ to compare its efficacy with $\mathrm{N}_{2} \mathrm{O} 70 \%$. We also did not record whether $\mathrm{N}_{2} \mathrm{O} 50 \%$ was administered via continuous flow or fixed valve (Entonox). However, in our department Entonox is used very rarely due to the absence of a scavenging system and its age limitations. Finally, it must be recognised that a number of procedures under $\mathrm{N}_{2} \mathrm{O}$ during the study period were missed or had incomplete documentation of scores, and were therefore omitted from final analysis. However, the age distribution and diagnoses of patients with incomplete scores who were excluded from analysis were similar to the study group.

\section{CONCLUSIONS}

Our data support the role of $\mathrm{N}_{2} \mathrm{O}$ for PSA in the ED. Parents and ED staff are in general satisfied with the level of analgesia provided. However, we must also conclude that $\mathrm{N}_{2} \mathrm{O}$ alone may not be the ideal drug in very painful procedures; further research into adjunctive analgesia is therefore warranted.

Funding: Grant support was received from the Victor Smorgon Charitable Fund, Melbourne, Victoria, Australia.

Competing interests: None.

Ethics approval: This study was approved by the hospital human research ethics committee.

Patient consent: Obtained.

\section{REFERENCES}

1. Krauss B, Green SM. Procedural sedation and analgesia in children (see comment). Lancet 2006;367:766-80.

2. Burton JH, Auble TE, Fuchs SM. Effectiveness of $50 \%$ nitrous oxide/50\% oxygen during laceration repair in children. Acad Emerg Med 1998;5:1191-8.

3. Hennrikus WL, Simpson RB, Klingelberger CE, et al. Self-administered nitrous oxide analgesia for pediatric fracture reductions. J Pediatr Orthoped 1994;14:538-42.

4. Luhmann JD, Schootman M, Luhmann SJ, et al. A randomized comparison of nitrous oxide plus hematoma block versus ketamine plus midazolam for emergency department forearm fracture reduction in children. Pediatrics 2006:118:e1078-86.

5. Yeo ST, Holdcroft A, Yentis SM, et al. Analgesia with sevoflurane during labour: ii. Sevoflurane compared with Entonox for labour analgesia (see comment). Br J Anaesth 2007:98:110-15.

6. Annequin D, Carbajal R, Chauvin P, et al. Fixed 50\% nitrous oxide oxygen mixture for painful procedures: a French survey. Pediatrics 2000;105:E47.

7. Krauss B. Continuous-flow nitrous oxide: searching for the ideal procedural anxiolytic for toddlers. Ann Emerg Med 2001;37:61-2.

8. Krauss B, Green SM. Sedation and analgesia for procedures in children. N Eng/ J Med 2000;342:938-45.

9. Frampton A, Browne GJ, Lam LT, et al. Nurse administered relative analgesia using high concentration nitrous oxide to facilitate minor procedures in children in an emergency department (see comment). Emerg Med J 2003;20:410-13.

10. Zier JL, Drake GJ, McCormick PC, et al. Case-series of nurse-administered nitrous oxide for urinary catheterisation in children. Anesth Analg 2007;104:876-9.

11. Hoffman GM, Nowakowski R, Troshynski TJ, et al. Risk reduction in pediatric procedural sedation by application of an American Academy of Pediatrics/American Society of Anesthesiologists process model. Pediatrics 2002;109:236-43.

12. Cohen LL, Lemanek K, Blocent RL, et al. Evidence-based assessment of pediatric pain. J Pediatr Psychol 2007;1-17.

13. Gallagher EJ, Liebman M, Bijur PE. Prospective validation of clinically important changes in pain severity measured on a visual analog scale. Ann Emerg Med 2001;38:633-8.

14. Powell CV, Kelly AM, Williams A. Determining the minimum clinically significant difference in visual analog pain score for children. Ann Emerg Med 2001;37:28-31.

15. Hicks CL, von Baeyer CL, Spafford PA, et al. The Faces Pain Scale-Revised: toward a common metric in pediatric pain measurement. Pain 2001;93:173-83.

16. Bieri D, Reeve RA, Champion GD, et al. The Faces Pain Scale for the self-assessment of the severity of pain experienced by children: development, initial validation, and preliminary investigation for ratio scale properties. Pain 1990;41:139-50.

17. Chambers C, Craig KD. An intrusive impact of anchors in children's faces pain scales. Pain 1998;78:27-37. 
18. Evans JK, Buckley SL, Alexander AH, et al. Analgesia for the reduction of fractures in children: a comparison of nitrous oxide with intramuscular sedation. J Pediatr Orthoped 1995;15:73-7.

19. Gregory PR, Sullivan JA. Nitrous oxide compared with intravenous regional anesthesia in pediatric forearm fracture manipulation. J Pediatr Orthoped 1996;16:187-91.

20. Luhmann JD, Kennedy RM, Porter FL, et al. A randomized clinical trial of continuousflow nitrous oxide and midazolam for sedation of young children during laceration repair. Ann Emerg Med 2001;37:20-7.

21. Lyratzopoulos G, Blain KM. Inhalation sedation with nitrous oxide as an alternative to dental general anaesthesia for children. J Public Health Med 2003;25:303-12.

22. Wattenmaker I, Kasses JR, McGravey A. Self-administered nitrous oxide for fracture reduction in children in an emergency room setting. $J$ Orthopaed Trauma 1990;4:35-8

23. Babl FE, Oakley E, Seaman C, et al. High concentration nitrous oxide for procedural sedation in children: adverse events and depth of sedation. Pediatrics 2008;121:e528-32
24. Babl FE, Puspitadewi A, Barnett $P$, et al. Preprocedural fasting state and adverse events in children receiving nitrous oxide for procedural sedation and analgesia. Pediatr Emerg Care 2005;21:736-43.

25. Hennrikus WL, Shin AY, Klingelberger CE. Self-administered nitrous oxide and a haematoma block for analgesia in the outpatient reduction of fractures in children. J Bone Joint Surg-American vol 1995;77:335-9.

26. Cravero JP, Blike GT, Beach $\mathrm{M}$, et al. Incidence and nature of adverse events during pediatric sedation/anesthesia for procedures outside the operating room: report from the Pediatric Sedation Research Consortium. Pediatrics 2006;118:1087-96.

27. Gerhardt RT, King KM, Wiegert RS. Inhaled nitrous oxide versus placebo as an analgesic and anxiolytic adjunct to peripheral intravenous cannulation. Am J Emerg Med 2001;19:492-4.

28. Borland $\mathbf{M}$, Jacobs I, King B, et al. A randomized controlled trial comparing intranasal fentanyl to intravenous morphine for managing acute pain in children in the emergency department. Ann Emerg Med 2007:49:335-40.

29. Miner JR, Krauss B. Procedural sedation and analgesia research: state of the art. Acad Emerg Med 2007;14:170-8.

\section{Emergency Medicine in the Developing World}

Cape Town, 23-26 November 2009

The Emergency Medicine Society of South Africa (EMSSA) is delighted to announce the second Emergency Medicine in the Developing World conference. All aspects of emergency care will be covered, with the main theme of this event being Disaster and Mass Gathering Medicine in a Developing World Setting.

Further details: http://EMSSA2009.co.za or contact Belinda Chapman (belinda.chapman@uct.ac.za) 